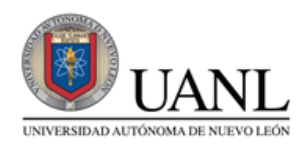
(9) FACPYA
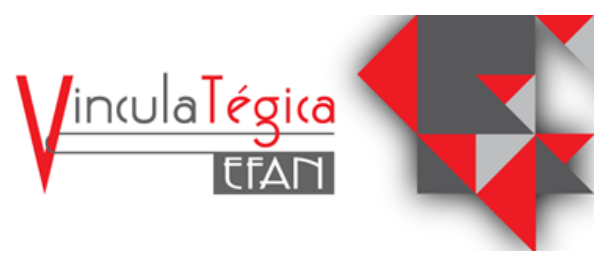

\title{
Las PyMES dirigidas por mujeres en Puebla: los retos ante la crisis económica
}

\author{
Rocío González Pereyra ${ }^{1}$ y Francisco Sánchez Espinoza ${ }^{2}$ \\ ${ }^{1}$ Benemérita Universidad Autónoma de Puebla, rocio.pereyra@outlook.com, Av. San Claudio, Ciudad \\ Universitaria, 2295500. \\ ${ }^{2}$ Benemérita Universidad Autónoma de Puebla, frasaes_7@hotmail.com, Av.San Claudio,Ciudad \\ Universitaria, 2295500.
}

Información del artículo revisado por pares

Fecha de aceptación: junio-2021

Fecha de publicación en línea: diciembre-2021

DOI: https://doi.org/10.29105/vtga7.2-15

\section{Resumen}

Recientes estudios relativos a la genealogía de las mujeres reportan una progresiva incorporación de éstas en las actividades empresariales. $\mathrm{Mi}$ intención es ocuparme de tales aspectos, con la finalidad de mostrar su relevancia en la investigación de la situación de las mujeres empresarias en el desarrollo local poblano. El que ellas se integren a ese ámbito es un fenómeno interesante de indagar, ya que en su decisión inciden elementos de orden social y cultural muy sugerentes para el análisis de la participación económica femenina, el mercado de trabajo y el desarrollo empresarial

Palabras clave: PyMES, crisis, empresarias, JEL: J01.

\section{INTRODUCCIÓN}

La oferta de trabajo, ha disminuido en todo el mundo provocada por la pandemia covid-19. En los países centrales y periféricos se ha manifestado una disminución del crecimiento económico y con ello menor obtención de puestos de trabajo y salarios competitivos. La oferta de ocupación en México no es suficiente para dar cobertura a la población en edad de trabajar.

\begin{abstract}
Recent studies on the genealogy of women report a progressive incorporation of women into business activities. My intention is to deal with such aspects, in order to show their relevance in the investigation of the situation of women entrepreneurs in the local development of Puebla. Their integration into this field is an interesting phenomenon to investigate, since very suggestive elements of a social and cultural order affect their decision for the analysis of female economic participation, the labor market and business development.
\end{abstract}

Keywords: local development, crisis, businesswomen JEL: J01.

Hoy, la pregunta se dirige a los procesos de reconversión y transformación empresarial ante la crisis pandémica. Tales como: El grado de inversión extrajera que se pueda captar, política económica que lleve a México a generar competitividad por parte de las empresas, políticas fiscales que incentiven a las PyMES y innovaciones en los mecanismos de servicio y estructura del trabajo.

Por lo anterior, se considera pertinente centrarse en rubros que están presentes en la 
relación entre mujeres, trabajo y desarrollo local; con ello me refiero a todo lo que permea este nexo, como la división sexual del trabajo, la doble jornada y la segregación laboral. Por ese motivo, se aplicó un cuestionarioentrevista, debido a la escasa información empírica que nutra a la situación de mujeres emprendedoras. De tal manera que las respuestas dotaron de información para entender la identidad de género de las empresarias $\mathrm{y}$, por otro lado, dar una explicación sobre cómo se desarrollaron sus trayectorias laborales y sus escenarios ante la crisis que estamos enfrentando.

El presente trabajo se presenta en tres apartados. En el primero, se presenta la discusión del marco teórico-conceptual que entraña el análisis de las empresariasPosteriormente, se describe la propuesta metodológica concebida en el desarrollo de todo el trabajo. Subrayo que gracias a las entrevistas a profundidad establecí una estrecha relación de confianza con mis informantes. Por último, se realizaron el análisis de las empresarias, su actividad laboral y el desarrollo local.

\section{REFERENTES TEÓRICOS Y CONCEPTUALES}

Las investigaciones empíricas de Zabludovsky muestran la incompatibilidad de los datos proporcionados por las distintas fuentes censales del país y también ponen en evidencia la escasa producción académica sobre las empresarias mexicanas. Así pues, para los fines de esta investigación sigo la definición de empresaria propuesta por Zabludovsky (2001: 39): "Aquella mujer que es propietaria y dirigente de su empresa y que además contrata por lo menos un trabajador asalariado dentro de la misma". En esta definición se dejan a un lado las concepciones teóricas de la Sociología comprensiva que, como apuntan las corrientes schumpeteriana y weberiana, vinculan la concepción de empresario con ciertas actitudes y orientaciones de la acción, tales como la toma de riesgos y el sentido de creatividad e innovación

En diversos estudios, las empresarias entrevistadas coinciden en proporcionar las siguientes razones por las que decidieron integrarse al mundo laboral en esta modalidad:

a). Necesidad de mejorar su nivel de vida y obtener ingresos propios.

b). Experiencia poco satisfactoria en el desempeño profesional.

c). Consideran que establecer una empresa propia es la única opción viable para integrarse a la actividad económica.

d). Flexibilidad de horario para atender a su familia.

e). Búsqueda de independencia.

f). Gusto por la actividad que realiza en su empresa.

g). Búsqueda de superación.

h). Por la pérdida del empleo anterior.

i). Por seguir la tradición en el negocio familiar.

Varias investigaciones constatan que cuando las mujeres pretenden desempeñarse en otros ámbitos reproducen actitudes que refuerzan su imagen tradicional. Debido a ello surge una variedad de matices en la conformación de nuevas identidades femeninas. A diferencia de los hombres, para desarrollar su profesión las mujeres tienen que esquivar una serie de obstáculos que se les presentan en el entorno familiar y laboral, y lo mismo les ocurre cuando deciden fundar un negocio.

Es innegable que hoy existen más oportunidades de acceso y permanencia en un trabajo para las mujeres, así como también se han abierto nuevos caminos para la participación de las mujeres en la política y para ascender a más altos niveles de educación. De conformidad con lo expuesto, investigadores como Rendón y Pedrero (1975), García y Oliveira (1994), Pacheco y Blanco (2002b), Pacheco (2003) y Oliveira y Ariza (1999), han tomado como tema central de sus estudios el pasado laboral de las mujeres empresarias y su participación en las actividades extradomésticas. Las explicaciones de estos autores destacan la influencia que ejercen las diversas transformaciones económicas, políticas, demográficas y sociales en las trayectorias de vida de los individuos. 
Para que las mujeres empresarias en México sean una realidad, es condición indispensable que existan redes de acción entre individuos y grupos; por ese motivo, es insoslayable saber cómo circulan, se afianzan o se redefinen pautas de consenso, de solidaridad $o$ de enfrentamiento que determinan la emergencia de éstas en una actividad económica a la que no siempre tuvieron acceso.

El cambio que ha provocado en la sociedad la incorporación masiva de la mujer a la educación, la cultura y el trabajo ha supuesto una transformación nodal en las relaciones sociales.

La participación de la mujer en el mundo laboral no se ha limitado - y cada vez más se confirma este hecho- a un simple proceso de imitar a los hombres, sino a un genuino intento de las mujeres de hacer compatible su desarrollo personal con el familiar, que si bien supone un enriquecimiento como persona, también crea dificultades e incompatibilidades que a veces resultan difíciles de superar y con frecuencia son motivo de discriminación en el trabajo. Una de las variables importantes por las que se argumenta que las mujeres no acceden a puestos ejecutivos es que esta actividad requiere tiempo completo. En primer lugar, aparecen como factores explícitos y externos los fuertes condicionamientos familiares que tienen las mujeres en su participación laboral. En efecto, la asignación de roles derivada de la construcción del género en la sociedad patriarcal impone a las mujeres el trabajo de reproducción.

Dentro de este proceso, es indiscutible que la expansión de las ciudades, provocada por el crecimiento de la población, ha generado nuevos ritmos de vida en las urbes: los horarios de trabajo, la escuela y el comercio modifican la organización familiar y transforman los modelos existentes; la distancia de la casa a la escuela o al trabajo, junto con la necesidad de que cada vez más mujeres trabajen fuera del hogar, ya sea para completar el presupuesto familiar o por ser el único sostén de la familia, son cambios que se han concebido en la vida cotidiana de las mujeres.
En esta dirección, el concepto de desarrollo local, es de gran relevancia, pues considera que: "Es el resultado de una acción de los actores o agentes que inciden (con sus decisiones) en el desarrollo de un territorio determinado. Estas decisiones no solamente se toman a escala local, sino que algunas se toman en otra escala (por ejemplo, a nivel nacional o internacional) e inciden en el desarrollo de un territorio. La preeminencia de las decisiones de los actores locales, por sobre otras decisiones que no responden a los intereses locales, es lo que define un proceso de desarrollo local (Massolo, 2016:14)."

Se entiende que las empresarias como actores locales, no se presentan de manera individual, sino forman parte de un grupo, cuyas acciones se desarrollan en un campo de la sociedad local, y que en los espacios político, económico y social son capaces de generar propuestas en torno a capitalizar de manera positiva las potencialidades locales (Massolo, 2016).

Ante la crisis pandémica, un gran número de mujeres ha entrado al terreno de los negocios. En el municipio de Puebla, la presencia de emprendedoras es cada día más evidente. En el sector terciario de la economía, las encontramos participando activamente en servicios de hospedaje, de alimentos preparados (restaurantes, fondas), de recreación (bares y discotecas), comercio al menudeo $\mathrm{y}$, recientemente, en actividades novedosas como los centros de spa (masajes, baños de temazcal, etcétera), centros de meditación y renta de equipos de computación con conexión a Internet.

Un panorama de diversidad, se presenta en la participación de la población ocupada en función de su actividad laboral, se tiene que casi tres quintas partes del total (57.1\%), esto es, poco más de 1 millón 658 mil son subordinadas y remuneradas; 753 mil (25.9\%) trabajan por su cuenta sin emplear personal pagado; más de 338 mil personas (11.7\%) no recibe remuneración alguna, y solo 155 mil (5.3\%) son propietarias de los bienes de producción con personal a su cargo (ENOE,2019). 
Bajo esta mirada, existen importantes diferencias entre hombres y mujeres, así tenemos que entre el personal subordinado y remunerado, $61.3 \%$ son varones y $38.7 \%$ son mujeres; por cuenta propia ellos son $62.0 \%$ y ellas $38.0 \%$, mientras que en empleadores/as los porcentajes son 84.8 y 15.2 respectivamente. La posición ocupacional donde las mujeres son mayoría es en las actividades no remuneradas, con $58.3 \%$ por $41.7 \%$ de los hombres (ENOE, 2019).

La reflexión sobre estos complejos escenarios de crisis recurrentes puede poner al descubierto cómo se ha desarrollado la economía global-local en la que prevalece la incertidumbre respecto del destino que tendrán las mujeres y los hombres que buscan otros canales para insertarse en la economía. En tiempos de agudas crisis, en términos de los gestores, familias y trabajadores que operan en México, se evidencia la dificultad que tienen las entidades gubernamentales responsables para poner en marcha políticas económicas eficientes y de largo plazo, para el heterogéneo contingente que conforman estas empresas en México. Hasta hace dos años no se había logrado avances sustentables en un proceso de mejora continua de las condiciones de trabajo que beneficie a los involucrados inmediatos, así como a las regiones donde las empresas se localizan, y el panorama actual es incierto.

\section{ALCANCE METODOLÓGICO}

En este trabajo me propuse reconstruir la historia de vida de las mujeres emprendedoras, tomando como contexto específico la ciudad de Puebla. La intención es ampliar otras dimensiones ocupacionales de mujeres, entendiendo que ese concepto puede ser un eje de referencia válido para el estudio de las mujeres de negocios.

El recorte metodológico de este trabajo propone la entrevista a profundidad, que es una de las aliadas más eficaces cuando se carecen de datos empíricos, ya que a través de ella se logran niveles de entendimiento de gran perspicacia, los cuales se incrementan notablemente conforme avanza la investigación, se multiplican las sesiones de diálogo y se logra una mayor intimidad y confianza con los entrevistados. Aclaro que entiendo el término entrevista como lo expresa Vela (2001: 66): "Se ha definido la entrevista como una situación construida o creada con el fin específico de que un individuo pueda expresar, al menos en una conversación, ciertas partes esenciales sobre sus referencias pasadas y/o presentes, así como sobre sus anticipaciones e intenciones futuras. En este sentido, la entrevista es, ante todo, un mecanismo controlado donde interactúan personas; un entrevistado que transmite información, y un entrevistador que la recibe, y entre ellos existe un proceso de intercambio simbólico que retroalimenta este proceso".

Siendo que para un estudio sobre los significados y prácticas de emprendedoras en una sociedad particular - la poblana - se precisa el seguimiento de las trayectorias de vida dentro de un marco cultural que las clasifique y defina, el diseño, planeación y ejecución de entrevistas a profundidad se presentan como particularmente fructíferas en tanto herramientas de reconstrucción del sentido y las valoraciones que los individuos otorgan a sus conductas. Taylor y Bogdan definen la entrevista de la siguiente manera: "[la entrevista es] una técnica de investigación cualitativa [consistente en] encuentros repetidos, cara a cara, entre, un investigador y sus informantes, los cuales se orientan a entender las perspectivas del entrevistado sobre su vida, experiencia o situaciones personales tal y como son expresadas por sus propias palabras (cit. en Vela, 2001: 75)"

La hipótesis que respalda mi estudio es que las trayectorias de las personas están interrelacionadas. Algunas investigaciones ahondan en la concepción de la mujer como un entramado de situaciones y relaciones que definen trayectorias de vida distintas. Con el aumento de la participación de la mujer en el mercado laboral se incorpora la perspectiva de curso de vida para estudiar las trayectorias laborales de la mujer, de acuerdo con sus otras trayectorias y sus etapas como persona: niñez, adolescencia, vida adulta y vejez. El género es, innegablemente, un eje de diferenciación 
entre las personas, además de la edad, la etnia y el grupo social de origen.

Diversos especialistas han argumentado que el mayor grado de instrucción entre las mujeres las lleva a concebir nuevas conceptualizaciones de la vida, actitudes y creencias, y es un factor dinamizador del cambio. En este sentido, es importan destacar los distintos orígenes sociales de las mujeres elegidas para la muestra, con el fin de conocer si hay otros factores, aparte del grado de instrucción alcanzado, que resultan determinantes tanto en sus prácticas como en el significado que las mujeres de la muestra le confieren al ámbito laboral, la vida en pareja y la maternidad. También profundicé en factores que pueden dificultar ese cambio y perpetuar formas tradicionales de acción que las acercan a las generaciones anteriores.

El estudio de la acción de las mujeres se ve enriquecido si se toma en cuenta la interpretación que ellas hacen de su vida cotidiana, pues abre determinadas líneas de reflexión que parten del sentido común para entender el escenario y el cambio social. Las acciones observables y manifiestas de las personas posibilitan estudiar a esas mujeres en sociedad. Todo esto constituye un conocimiento fundamental para comprender las transformaciones en la familia, formas de intimidad, creencias e incluso la idea de futuro.

Para delimitar la unidad de observación sólo tomé en cuenta a las empresarias que se encuentran al frente de empresas formalmente establecidas y no de aquellas que pertenecen al comercio informal. El procedimiento para elegir a los sujetos de investigación correspondió a un muestreo no probabilístico, ya que éste es idóneo para obtener información de manera rápida y a un bajo costo, así que elegí una muestra por conveniencia (Sánchez, 2010: 65).

El criterio utilizado para la selección de las mujeres empresarias se hizo de acuerdo a la definición de empresaria que aporta Zabludovsky (2001: 39), es decir, "Aquella mujer que es propietaria y dirigente de su empresa y que además contrata por lo menos a un trabajador asalariado dentro de la misma".
Este primer cuestionario-entrevista presenta preguntas de respuestas cerradas y preguntas de respuestas abiertas. La ventaja de este cuestionario-entrevista es que permite, por un lado, dar respuestas rápidas para algunas preguntas, sobre todo, de aquellas que proporcionan información cuantitativa; por otro lado, las demás preguntas posibilitaron que las personas se pudieran extender hasta donde lo desearan y, en ese momento, yo podía intervenir con otras interrogantes en función de lo expresado.

\section{LOS HALLAZGOS ENCONTRADOS}

Este apartado tiene como propósito abordar las relaciones en el ámbito poco explorado de la participación de mujeres en el emprendimiento. Pondré énfasis en los factores y conflictos que estas mujeres enfrentan al iniciar y desarrollar una empresa.

La mayoría de las mujeres entrevistadas, como Concepción, Angélica, Eva Guadalupe, María, Georgina y Patricia, vivían en un núcleo familiar tradicional con arraigadas prácticas de género y patriarcado. Las entrevistadas manifestaron que habían vivido con la idea de que ellas algún día trabajarían, ya que crecieron en un ambiente familiar en el que su madre trabajaba, lo cual influyó, sin duda, en su decisión de insertarse al mercado laboral.

Esto es lo que Angélica refirió acerca de cómo pensó su iniciación al mundo de los negocios: Inicié mi actividad cuando me casé y decidimos irnos a Estados Unidos, al ver que su sueldo no alcanzaba para tener una vida mejor, me angustié, ya que la vida en ese país es cara, y cuando tuvimos a nuestro primer hijo fue más difícil, no sabía cómo ayudar a mi esposo y a mi familia y, la verdad, estaba desesperada. Un familiar me presentó con un joyero en el Distrito Federal y me dio un crédito para vender oro: era un gran riesgo, pero lo tomé. El vender oro es muy fácil, ya que las personas obviamente como ganan en dólares, es más fácil que te vayan abonando, cada semana sus treinta o cuarenta dólares, y cuando terminan de pagar, te piden otra cosa. Una de las razones primordiales es que los que no tienen papeles, no pueden salir a las grandes plazas a comprar, por miedo, es por 
ello que al llegar yo con mi mercancía y tocar a su puerta directamente les era más fácil y a mí me convenía, pues me hice de algunos clientes (Angélica, 49 años).

Concepción, por su parte, expresa abiertamente la influencia de su decisión sobre su propia vida, especialmente su inclusión al mundo empresarial:

Cuando estuve en el gobierno, tomé un curso de repostería; fue cuando empecé a vender pasteles; también vendí ropa en el instituto en donde yo trabajaba. Me fue muy bien, incluso a veces me contrataban para algún banquete. Cuando tenía los pedidos era de ir a la central de abastos, y regresar con mis bolsas cargadas de harina, huevos, fruta, azúcar, etc. A veces, sin mentir, eran las dos de la mañana y seguía haciendo pasteles; era sólo dormir unas tres o cuatro horas y levantarte, bañarte e irte al trabajo. A veces eran dos o tres a la semana, pero eran chiquitos. Después comencé a hacer más grandes: para boda, quince años, tres años, bautizos, panqués, empanadas también me pedían, es cuando decidí en primer lugar, contratar a alguien que me ayudara y seguir haciendo pasteles (Concepción, 55 años).

Otra de las razones que se aducen acerca de qué motiva a las mujeres a participar en actividades empresariales es la estructura socioeconómica desfavorable. Tal situación ha provocado que las empresas exijan de sus empleados más entrega, un mayor dinamismo y una mayor productividad. La transformación del trabajo en esta nueva trama económica provoca tensiones que exigen mucho de los empleados y de sus familias. Precisamente a esta situación se refiere Eva:

Cuando salí de la licenciatura, nunca pensé que el trabajo me absorbiera todo el tiempo, sentía que me consumía, nunca tenía tiempo de nada, trabajaba de lunes a domingo en una tienda donde nunca se cerraba, era la contadora y administradora del negocio, tenía muchas responsabilidades con el dinero, depositaba dinero, pagaba nómina, llevaba la contabilidad, entraba a las nueve de la mañana y no tenía hora de salida. Durante ese tiempo tuve a mi primera hija, y aunque no quería el dueño, tomé mis días de incapacidad, pero antes tuve que trabajar más para que me autorizaran la incapacidad; lo más importante es que no veía a mi hija, no tenía vida familiar, mi único día de descanso eran los martes. Decidí poner mi negocio cuando me liquidaron de la empresa donde trabajaba, ya que tenía diez años de antigüedad. Me siento afortunada, ya que me dieron mi liquidación y con ese dinero inicié mi tiendita de abarrotes, pero no fue fácil, ya que me ha costado mucho trabajo sostenerme (Eva, 40 años).

Las empresas dirigidas por mujeres no pueden ser consideradas aisladamente del entorno económico y sociocultural en que se desenvuelven. Ese entorno puede ser propicio o no para la inserción al mercado laboral de las empresarias. Los valores sociales, tales como la subestimación de la función económica de las mujeres y la existencia de estereotipos en cuanto a las funciones propias de cada sexo influye mucho a la hora de tomar una determinación sobre el futuro laboral. Ése es el caso de Guadalupe, quien nació en la Ciudad de México en 1930. Al momento de entrevistarla tenía 83 años, y a una pregunta que le hice respondió lo siguiente: Yo soy una mujer de trabajo. Yo trabajabacomo secretaria en el Ayuntamiento de aquí de Puebla. Perdone la modestia, o la vanidad, pero es que yo fui "excelente secretaria". Ahi trabaje durante seis años. Hasta que un día mi novio de permiso me propuso matrimonio, él me propuso dejar de trabajar y que le ayudara en su ferretería, ya que se vería muy mal que siendo casados siguiera trabajando. Me casé de veintiún años, pensaba que ya no me casaría porque todas mis amigas y familiares ya estaban casadas y con hijos, ya era grande cuando me casé. Para mí fue muy bueno que pudiera seguir trabajando con mi esposo y a la vez atender mi hogar, por lo que aprendí muy pronto el manejo de la ferretería. Le hacía a todo, un rato en la caja, otro acomodando mercancía en los estantes y atendiendo a mis hijos y marido. Hasta que él se puso grave y falleció; en ese momento asumi toda la responsabilidad de mis hijos y de la ferretería, que era el único sustento de mi familia. Mis familiares decían que la vendiera, que me dedicara a otra cosa porque no era un negocio para una mujer, pero no 
hice caso y hasta la fecha estoy aquí (Guadalupe, 83 años).

Con estas nuevas pautas sociales, culturales y políticas, las ejecutivas que han alcanzado espacios de poder dentro de las grandes compañías, las que están a la cabeza de las decisiones operativas, de personal y administrativas en industrias, ya sea de la transformación o de los sectores de servicios y bancario, están abriendo espacios para otras mujeres. Su ejercicio dentro de estas empresas cuestiona las concepciones tradicionales que consideran a la mujer inhabilitada para desempeñarse en puestos de dirección, y conduce a revaluar la cultura que negaba de forma implícita la inclusión de mujeres en dichos espacios.

Otra barrera más es que a menudo la actividad empresarial de las mujeres es imperceptible, pues muchas de ellas laboran desde su domicilio. Esta forma de trabajar a veces les impide enterarse de la existencia de programas para el desarrollo de las capacidades empresariales. A partir de estas circunstancias, se vuelve imperioso desarrollar programas especiales para las Mujeres emprendedoras que trabajan desde su hogar. Al respecto, Julieta cuenta lo siguiente: Yo tenía que ajustarme al horario de la escuela de mi hijo, y hacer todo lo posible por cumplir con mi trabajo y a la vez atender a mi familia. Es decir, pedir permiso para ir por mi hijo y regresar por la tarde para cumplir las ocho horas al día, y si me quedaba más de ocho horas eso no me lo tomaban en cuenta, por lo que decidí abrir la cochera de mi casa y vender comida. No quería tener un trabajo que me impidiera estar con mi familia, bueno eso de pensar que alguien que tiene un negocio puede abrir y cerrar cuando quiera es mentira, es muy esclavizante. Si no abres un día o no tienes horarios estrictos de abrir y cerrar, la gente se va (Julieta, 45 años).

${ }^{1}$ En el año 2000, Pérez Lizaur llevó a cabo en México uno de los trabajos pioneros sobre este tema; se trata de un estudio de corte antropológico. La autora tuvo como propósito elucidar las razones por las cuales las mujeres ejecutivas permanecían o renunciaban a su trabajo. Estas aportaciones coinciden con las de Arango, Viveros y Bernal para
García (2007) señala que la responsabilidad de la familia, que recae principalmente en las mujeres, es la causa que les impide obtener mayores logros laborales y acceder a puestos más altos, al menos así sucede en las sociedades occidentalizadas. Es decir, los puestos directivos no sólo se alcanzan por medio de méritos y diplomas, sino mediante una lucha de poder que rodea a la jerarquía masculina.

En este sentido, los motivos por los cuales las mujeres que ocupan puestos ejecutivos de alto nivel deciden permanecer o abandonar su trabajo se deben a la complejidad que prevalece en el mundo corporativo, en donde las tensiones entre trabajo y familia se provocan, en gran medida, por la intolerancia y falta de flexibilidad en los horarios a los que se ven sometidas ${ }^{1}$. Con frecuencia, las mujeres que se encuentran en esta situación, recurren a estrategias en las que la familia extensa juega un papel fundamental (Serna, 2012: 21), así lo revela Maricarmen: Los puestos de dirección son muy complicados. Para mí fue un reto cuando me nombraron gerente del banco, porque el hecho de ser mujer se dificulta, en el tiempo, en la relación de pareja. Mi esposo, por cuestiones de machismo o inseguridad, empezó a cambiar. Todo esto porque yo tenía un sueldo mayor que el de él; cada vez que llegaba la quincena, me quitaba el dinero y él era el que disponía de todo, mientras que yo tenía que adaptarme a lo que él decidiera. Este tiempo fue muy triste para mí; él tenía inseguridades, el día a día era muy cansado, los problemas eran cada vez más frecuentes y llegó un momento incluso que él me decía cosas que me lastimaban, como por ejemplo: que me había embarazado para atraparlo o que lo engañaba. Por todos estos problemas decidí renunciar a mi trabajo, y como fue renuncia voluntaria no me dieron nada más que las gracias, y pedí un préstamo ahí mismo

el caso de países del Cono Sur respecto a la fricción en cuanto al desempeño laboral en actividades ejecutivas y el papel que ejerce la cuestión familiar en la condición de madre trabajadora. Esto también ha sido señalado por Serna (2003). 
en el banco. No tenía idea de lo que iba a hacer con ese dinero, que era poco. No tengo ningún familiar que se dedicara al comercio, pero pensé en comprar toallas, sábanas, manteles y venderlos. En ese momento empecé a hacer negocio (Maricarmen, 49 años).

Las investigaciones realizadas acerca de la flexibilidad del trabajo se han orientado al análisis de los impactos en el sector empresarial y sobre aspectos tales como la calificación, la formación profesional, el uso de nuevas tecnologías, la reorganización del trabajo y, más recientemente, sobre los distritos industriales y los encadenamientos productivos, entre otros (Rendón, 1993). Sobre esta discusión es difícil encontrar una relación entre la participación masculina y la femenina, a excepción de algunos estudios en los que se ha rescatado la importancia de la presencia de las mujeres en procesos de flexibilidad, aunque en la mayoría de los estudios se reconoce la figura del trabajador encarnado en la figura del hombre como sujeto universal (De la O, 2004).

Los estudios de género abordan desde una perspectiva crítica la utilización de las dicotomías producción/reproducción, público/privado. Se cuestiona la visión del ámbito doméstico y reproductivo como femenino, privado y opuesto a la esfera de lo público-productivo, entendido como lo masculino, y la aceptación de la división sexual del trabajo (hombres-proveedores, mujeres-amas de casa) como algo natural e inherente al papel de las mujeres en nuestras sociedades. ${ }^{2}$ No obstante, se entiende que esta división sexual es una construcción sociohistórica susceptible de transformación (Yanagisako, 1999). En este sentido, sabemos que en la actualidad, principalmente en los países desarrollados, se ha perfilado una clara tendencia hacia una mayor participación de las mujeres en distintas esferas de lo social.

De manera particular, la segunda mitad del siglo XX fue testigo de importantes cambios en la familia que removieron las

${ }^{2}$ Las labores socialmente asignadas a las mujeres pueden influir en su incorporación al mercado laboral, inhibiéndola o fomentándola, de tal forma que, como lo constata la bibliografía existente en estructuras patriarcales. Uno de esos drásticos cambios se relaciona con el hecho de que una vez establecida la unión conyugal, se supone que hombres y mujeres cumplirán de manera cabal sus respectivos papeles de género que tan comúnmente se han estatuido, y que consisten básicamente en que el varón aporte el aprovisionamiento material de la familia y la mujer brinde resguardo y fidelidad a su marido. Al entenderse el matrimonio como una relación contractual de derechos y obligaciones, en la que cada una de las partes se compromete a satisfacer la esfera de actividades que le corresponde, en el momento en que ese equilibrio se rompe la parte afectada se encuentra en su derecho de resolver sus necesidades económicas de la forma en que considere conveniente, como explica Yolanda: Pienso que me tocó la misma suerte que mi mamá, ya que me tocó un hombre flojo. Él trabajó en unas oficinas de gobierno, pero desde que lo despidieron, según él ya no encontró trabajo y pedíamos dinero prestado para comer, hasta que un día pensé en tener abonados. También lavaba ajeno y planchaba. Entonces nos dejamos porque era muy irresponsable y porque quería mandar, siendo que no aportaba dinero. Con eso mantuve a mis hijos y les di estudios, la verdad es que me fue muy bien y con el tiempo puse esta lavandería y tintorería (Yolanda, 65 años).

Otro factor que caracteriza las interpretaciones acerca de la inserción de las mujeres en la actividad empresarial es la maternidad, que se ha definido como un espacio de anclaje genérico para la construcción de las mujeres como sujetos, debido a la especialización procreativa esencialmente del cuerpo femenino, el deseo de ser madre y el amor incondicional por los hijos. Así lo expresa Aurora: Mis papás se divorciaron cuando tenía cinco años. Primero fui a vivir con mi papá, luego ya con mi mamá. Pero desde siempre yo tenía muy definido que quería estudiar, entonces por ese lado no tuve

México, se considera que las mujeres no unidas y las unidas, con hijos mayores, enfrentan menos obstáculos para incorporarse al mercado de trabajo (García y Oliveira, 2006). 
conflictos. Pero me metí a trabajar porque me peleé con mi padre y era su manera de castigar: "Pues ya no te doy nada y hazle como puedas". Yo soy muy orgullosa y le dije: "Perfecto, no hay problema". Fue por eso que empecé a trabajar desde jovencita, no porque me muriera de ganas por hacerlo, pero luego me fascinó y estaba yo encantada. Siempre pensé en tener una familia, como no la tuve... ya que mis papás se divorciaron, deseaba casarme, tener hijos y cuidar a mi familia, porque pienso que las mujeres deben de cuidar a su familia e hijos, ya que para eso nacimos. Cuando me casé dejé de trabajar y me embaracé тиy rápido. Mi esposo afortunadamente y gracias a Dios tenía dinero para mantenernos él sólo, pero siempre se necesita más dinero, pero no me gustó mucho estar de ama de casa: es importante que uno tenga su propio dinero. Fue cuando le propuse a mi esposo que quería poner un negocio, inicié con una cocina económica, primero le vendí a mi familia y después fue creciendo y ahora tengo encargo de banquetes para fiestas muy grandes, no me dediqué totalmente al cuidado de mi familia. Ya que conforme el negocio fue creciendo, yo ya no podía estar con ellos, pero me entendían, ya que sabían que era por estar mejor económicamente (Aurora, 55 años).

El panorama en la última década, se han generado microemprendimientos que ha sido una habilidad muy popular entre las mujeres poblanas para poder salir adelante ante la crisis económica y desafiar los elevados niveles de desempleo de las mujeres y el de sus compañeros. Muchas de estas formas de ingresar a generar sus propios ingresos se ubican en el sector restaurantero, textil, artesanal y de la decoración. En muchos casos, surgen como una manera de aumentar los ingresos familiares. También hay empresarias que llegan a serlo casi de manera accidental, como por ejemplo, al heredar. Esto quiere decir que se incorporaron al trabajo como empresarias a consecuencia de problemáticas familiares muy localizadas, pero tampoco son arribistas o improvisadas, como comenta Cristina: Desde que recuerdo, siempre tuvimos el negocio de materiales para construcción, siempre crecí en este medio y le ayudé a mi papá; sabía quiénes eran los clientes, proveedores, trabajadores, que eran como de la familia. Desde chicos siempre, siempre compartimos esa responsabilidad de estar en el negocio y ayudar a mi papá; me acuerdo que por las tardes y el fin de semana ayudábamos a limpiar y ordenar cosas; también recuerdo que mi papá repetía constantemente: "Este medio es muy feo para las mujeres, para las niñas, así que tú cuando seas más grande ya no podrás venir porque es un ambiente de hombres"; y lo cumplió, porque cuando tenía quince años yo ya no fui al negocio. Mi mamá sólo se interesaba en su quehacer, nunca platicaba, quizá porque se casó muy chica, de catorce años; pero te cuento que terminé la licenciatura y empecé a trabajar, me casé y tuve tres hijos, siempre trabajé. Cuando mi papá ya no pudo atender el negocio, se quedó a cargo mi hermano, pues como es hombre, era el idóneo para seguir adelante con la actividad. Pero se gastaba el dinero y sinceramente no pudo sostener la empresa, y yo la recuperé, pagué las deudas que había adquirido con proveedores y aquí estoy a cargo de todo. Me siento orgullosa de seguir con lo que nos dejó mi padre, aunque no estuviera en sus planes que yo me hiciera cargo de esto (Cristina, 62 años).

El patriarcado es una estructura básica de todas las sociedades contemporáneas. Se caracteriza por la autoridad, impuesta desde las instituciones, de los hombres sobre las mujeres y sus hijos en la unidad familiar. Para que se ejerza esa autoridad el patriarcado debe dominar toda la organización de la sociedad.

Una perspectiva interesante para el análisis y la comprensión de la transformación del patriarcado, es la que propone Castells (2001), quien sostiene que el proceso que resume y concentra este cambio es la crisis de la familia patriarcal. Si ésta se desmoronara de forma gradual pero segura, todo el sistema del patriarcado, y el conjunto de nuestras vidas, serían transformadas. Desde luego, ésta es una idea pavorosa, y no sólo para los hombres. Por eso, el desafío al patriarcado es uno de los factores inductores más fuertes de los movimientos fundamentalistas que aspiran a restaurar el orden patriarcal; su reacción violenta podría alterar los procesos actuales de 
cambio cultural, ya que ninguna historia está escrita de antemano. En su análisis, este autor trata de determinar las causas de las formas tradicionales de la familia patriarcal, y para ello se detiene en examinar algunos indicadores. Concluye que las estadísticas, por sí solas, no pueden contar la historia de la crisis del patriarcado, pero cuando los cambios son tan amplios como para reflejarse en las estadísticas nacionales comparadas, cabe asumir con certeza su profundidad y rapidez (Castells, 2001: 122).

Intento demostrar lo que se ha denominado techo de cristal, que aparece como un conjunto de elementos subjetivos que impiden de manera generalizada el ascenso de las mujeres a posiciones altas dentro de las estructuras jerárquicas de las instituciones públicas o privadas. En este sentido, el techo de cristal representa un conjunto de estructuras simbólicas a partir de las cuales los hombres y las propias mujeres dificultan o impiden el trabajo de las mujeres en los espacios de poder. Así lo pone de manifiesto Beatriz: A mí me gustaba lo que hacía; siempre di más que los demás en mi anterior trabajo, me gradué de actuaría y trabajé diez años en una aseguradora. Fui representante regional. Mi experiencia fue muy difícil: nunca podremos ganarle a los hombres, ni siquiera a las mismas mujeres, porque te ven mal que andes en reuniones donde todos eran hombres. Fui tachada como "marimacha"; eso implicaba un doble reto, pues siempre hay caballeros que con desaire se niegan a ser mandados por una mujer; hay burlas, se cuentan chistes... por eso cada mañana, sentada ante mi escritorio, dejaba a un lado mis debilidades, porque las tenía y las tengo, y me mostraba fuerte. Así logré estar diez años, pero, ¿sabes qué paso?; ¿por qué ya no sigo ahí? Pues te diré que las decisiones se realizan en cenas, inclusive bares, pero ya no fue posible, ya que mi pareja se molestaba y literalmente me dijeron que yo no era apta para ocupar el puesto, y la verdad no quise aceptar otra cosa menor de la que había logrado, eso era regresar a una subdirección, no era justo. Para no hacerte más largo el asunto, me liquidaron y ahí pensé en invertir en una tienda de abarrotes, pero te confesaré algo: siempre pienso en cómo hubiera sido si aún trabajara en la aseguradora. Es algo que nunca podré saber (Beatriz, 59 años).

El fundamento de las estructuras simbólicas del techo de cristal es la cultura, en la que prevalece la percepción tradicional de las mujeres como la única responsable del cuidado de los hijos y la responsabilidad de los quehaceres domésticos. Al mismo tiempo, se reconoce el predominio de una cultura que define las expectativas de las mujeres, de tal forma que los valores que ellas forjan en sus procesos de socialización son elementos subjetivos de castración de la actitud femenina ante la ocupación en las estructuras de poder. Las funciones de liderazgo que hoy desempeñan las mujeres en empresas privadas, en la administración pública, la ciencia, la política y las artes aluden a un funcionamiento cultural y nos llevan a reconocer que ellas se han apropiado de símbolos que todavía aparecen en el campo del predominio masculino. En este caso, la incorporación de estas mujeres en nuevos espacios de poder se presenta dentro de transformaciones económicas, políticas y socioculturales de una sociedad que paulatinamente se incorpora a la modernidad (Serna, 2008).

Una de las vertientes que da respuesta a la inclusión de las mujeres en la actividad empresarial ha sido la inestabilidad laboral que afecta al núcleo y existencia misma de la construcción social trabajador/jefe/proveedor, la cual está muy enraizada en la sociedad contemporánea.

Esa construcción social está compuesta de una serie de pilares básicos que, en su conjunto, definen un "deber ser" que abarca las relaciones del trabajador en el ámbito familiar y laboral, así como las articulaciones entre ambos. Los principios básicos de tal construcción social son amenazados por la inestabilidad laboral; en sintonía con esto, Graciela refiere: Nunca olvidaré que fuimos pobres; mi esposo trabajó muchos años en Volkswagen en el área de hojalatería y pintura, hubo recorte de personal y fue entonces cuando lo despidieron, cuando fue lo de Estados Unidos de la guerra. No te voy a mentir, yo no sabía nada de negocio, nunca trabajé, sólo en la 
casa, pero te juro por Diosito que cuando uno está necesitado uno piensa y piensa qué vamos a hacer; no teníamos para la inscripción de mis hijos, son tres, y una noche se me ocurrió que con mi anafre y carbón podría vender chalupas. Esa decisión nos cambió la vida: dicen que cocino muy rico y mis chalupas son muy buenas, asífue como empecé en esto de la comida cuando a mi marido lo sacaron de la fábrica (Graciela, 40 años).

La explicación que dan algunas mujeres acerca de por qué se convirtieron en empresarias son distintas a las expuestas en los casos anteriores, en los que prevalece la necesidad de aumentar los ingresos para la manutención del hogar. Cuando el salario del jefe proveedor económico de familia es deficiente o tiene múltiples interrupciones, una de las principales alternativas que tiene el grupo doméstico es enviar integrantes al mercado laboral (García y Oliveira, 2001; Salles y Tuirán, 2009; Selby, 1990; Pacheco, 2001; Pedrero, 2003; Blanco, 2001); cuando así sucede, el papel de ama de casa-esposamadre, o el de hijos-estudiantes se altera, si no es que se disuelve. Esto ocurre cuando se trasladan esas responsabilidades a otros miembros de la familia.

Un hallazgo más del estudio que estoy comentando, es que cuando quien ejerce el rol de proveedor pierde su empleo, puede pasar más tiempo con su familia, de manera que interviene en las rutinas de su esposa e hijos y, por ende, también se involucra en el ejercicio de las funciones básicas de sus familiares.

El mundo de las empresarias no es diferente al de las otras mujeres trabajadoras. En distintos momentos y regiones ellas se han insertado al mundo laboral en los momentos en que las crisis regionales o nacionales han afectado los entornos laborales y sociales donde se desarrolla su vida familiar. El acontecimiento más documentado ha sido el del ingreso femenino al trabajo asalariado; en este contexto, los elementos que han servido de "ayuda" y complementariedad al ingreso familiar suelen encubrir, incluso por las mismas mujeres, los procesos de negociación y cambio de la identidad genérica, que son los que han hecho posible su incorporación al trabajo asalariado. Al criticar el poder masculino y sus resultados en el mundo que compartimos, vemos que no se trata de que las mujeres intenten, a su vez, dominar a los hombres, sustituyendo fases del patriarcado por fases de matriarcado, ya que la lucha es por la transformación del poder mismo, sus términos y sus condiciones, todo lo cual se apoya en una legislación que tome en cuenta los intereses femeninos. Menos aún se pretende anular las diferencias de los sexos para alcanzar la igualdad. Porque requerir que una sea igual a los que marcan el criterio que nos distingue y clasifica como distintos socialmente, traerá como consecuencia la imposibilidad misma de alcanzar tal igualdad, porque nunca cumpliríamos el criterio (Serna, 2010: 21).

También hay circunstancias que provocan que las mujeres participen en actividades empresariales enmarcadas en una estructura económica y social de dominación en la que ellas reciben un trato diferencial generalmente discriminatorio en razón de género. Las entrevistadas apuntaron siete razones que las habían llevado a integrarse al mundo empresarial, que admiten ser agrupadas como sigue:

1. Por necesidad o deseo de aumentar sus ingresos

2. Por una experiencia poco favorable en el ámbito laboral

3. Por considerar que administrar su tiempo para atender el hogar y la actividad económica a la vez era una buena opción

4. Por viudez

5. Porque su pareja no trabaja

6. Por haber recibido una herencia

7. Porque su pareja se quedó sin empleo.

De esta lista se desprende que en Puebla la presencia de las empresarias corresponde a una composición y perfil con clara orientación hacia sectores medios. Sin lugar a dudas, esto constituye un desafío importante y de largo alcance para el diseño y ejecución de las políticas públicas, como ya señalé. Pero es necesario precisar que al clasificar las razones que motivaron a las mujeres que formaron parte de la muestra de este estudio, no pretende hacer generalizaciones que cubran todas las 
posibles respuestas; sin embargo, hay coincidencias que se consideran pertinentes señalar. Al mismo tiempo, la trayectoria personal de estas mujeres prevalece como un papel clave en las decisiones que tomaron en lo concerniente a su futuro.

Cuadro 1

Razones para elegir la actividad empresarial

\begin{tabular}{|c|c|c|c|c|}
\hline Nombre/Edad & $\begin{array}{c}\text { Grado } \\
\text { académico }\end{array}$ & $\begin{array}{c}\text { Motivos para elegir ser } \\
\text { empresarias }\end{array}$ & Trabajos anteriores & Actividad \\
\hline $\begin{array}{c}\text { Eva } \\
(40 \text { años })\end{array}$ & Ninguno & $\begin{array}{c}\text { Su pareja se quedó sin } \\
\text { empleo }\end{array}$ & Ninguno & Restaurante \\
\hline $\begin{array}{l}\text { Graciela } \\
\text { (40 años) }\end{array}$ & Administradora & $\begin{array}{l}\text { La liquidaron de su } \\
\text { anterior trabajo y con ese } \\
\text { dinero puso su tienda de } \\
\text { abarrotes }\end{array}$ & $\begin{array}{l}\text { Administradora y } \\
\text { contadora en una } \\
\text { tienda de telas }\end{array}$ & Abarrotes \\
\hline $\begin{array}{c}\text { Julieta } \\
\text { (45 años) }\end{array}$ & Abogada & $\begin{array}{l}\text { Quería pasar más tiempo } \\
\text { con su familia }\end{array}$ & $\begin{array}{c}\text { Escribiente en un } \\
\text { despacho de } \\
\text { abogados }\end{array}$ & Restaurante \\
\hline $\begin{array}{l}\text { Angélica } \\
\text { (49 años) }\end{array}$ & Odontóloga & $\begin{array}{l}\text { Se fue a Estados Unidos y } \\
\text { el ingreso de su esposo era } \\
\text { insuficiente }\end{array}$ & Ninguna & $\begin{array}{l}\text { Comercio } \\
\text { Ropa }\end{array}$ \\
\hline $\begin{array}{l}\text { Carmen } \\
\text { (49 años) }\end{array}$ & Contadora & $\begin{array}{l}\text { Tenía problemas con su } \\
\text { esposo, ya que pasaba } \\
\text { mucho tiempo en el trabajo }\end{array}$ & Gerente de banco & $\begin{array}{l}\text { Venta de } \\
\text { blancos }\end{array}$ \\
\hline $\begin{array}{c}\text { Coni } \\
\text { (55 años })\end{array}$ & Secundaria & $\begin{array}{l}\text { Quería aportar más } \\
\text { ingresos a su familia }\end{array}$ & $\begin{array}{c}\text { Secretaria en empresa } \\
\text { de autopartes }\end{array}$ & Restaurante \\
\hline $\begin{array}{c}\text { Aurora } \\
(55 \text { años })\end{array}$ & Ninguna & $\begin{array}{l}\text { No podía ver a sus hijos, } \\
\text { ya que trabajaba todo el } \\
\text { día, y decidió dedicarse a } \\
\text { la repostería }\end{array}$ & $\begin{array}{l}\text { Secretaria en } \\
\text { gobierno }\end{array}$ & Pastelería \\
\hline $\begin{array}{l}\text { Beatriz } \\
\text { (59 años) }\end{array}$ & Administradora & Renunció a su trabajo & $\begin{array}{l}\text { Representante } \\
\text { regional de seguros }\end{array}$ & Abarrotes \\
\hline $\begin{array}{l}\text { Cristina } \\
\text { (62 años) }\end{array}$ & Psicóloga & Heredó la empresa & En la Procuraduría & Llantera \\
\hline $\begin{array}{l}\text { Yolanda } \\
\text { (65 años) }\end{array}$ & Primaria & Su pareja no trabajaba & Ninguno & $\begin{array}{l}\text { Lavandería y } \\
\text { tintorería }\end{array}$ \\
\hline $\begin{array}{c}\text { Lupita } \\
\text { (83 años) }\end{array}$ & Primaria & $\begin{array}{c}\text { Su esposo y ella iniciaron } \\
\text { la empresa }\end{array}$ & Ninguno & Hotel \\
\hline
\end{tabular}

Fuente: elaboración propia, basada en entrevistas con empresarias en Puebla, entre 2015 a 2017.

Para efectuar este estudio partí de la noción de que la conducta individual debe ser considerada como una elección más en el contexto de las relaciones sociales. Las estructuras de opciones siempre son específicas para las condiciones históricas e individuales, pero también de las familiares; ya que la familia es uno de los factores más importantes en la socialización de las personas, la toma de decisiones tales como la profesión, el trabajo, la pareja o la maternidad está vinculada a las referencias generacionales que las personas han tenido y que contribuyen a explicar la actual inserción de la mujer en el trabajo empresarial.

Los antecedentes referidos resultaron útiles, además, para comprender cómo estas mujeres, en su vida cotidiana, viven y definen la articulación de esas relaciones y cómo, en su calidad de bien intencionada (aunque restringida por el contexto), idea su trabajo y otras estrategias para renegociar aspectos de las relaciones de género en el seno de la unidad doméstica.

El riesgo que asumí en este trabajo y que a la vez es un aporte para los estudios de género radica en que, por un lado, abarqué varios momentos del tiempo y no sólo la sincronía del presente. Así también, incorporé las distintas etapas por las que estas mujeres empresarias pasaron desde la infancia hasta la vejez. De igual forma, tomé en cuenta las diferencias de género en las distintas trayectorias y papeles de las informantes, por lo que me fue posible identificar los cambios que se suscitaron en las funciones que realizan tanto las mujeres como los varones.

\section{CONCLUSIONES}

La actividad de las mujeres con poder 
económico no debe ser pensada como algo ajeno a la cotidianidad; si los estudiosos han sostenido que la realidad cultural pertenece a la vida práctica y pragmática de todos los días y de todas las horas del día; si se ha dicho que la historia es resultado de una serie de actos y la decisión que se encuentra permeada por la dimensión cultural; si se ha asegurado que la cultura inhibe o fomenta ciertos avances, es obvio que la rebelión de las mujeres debe estar atravesada por un cambio en lo cultural y los valores que le dan cuerpo a estas nuevas identidades. Por otra parte, comprobé que, en efecto, la participación femenina en la actividad empresarial se concentra en el sector comercio y servicios.

Hay bastantes argumentos de peso que se proponen explicar por qué las mujeres participan en actividades empresariales. Una de ella insiste en que hay una estructura económica que deriva en la pérdida de puestos de trabajo, bajos salarios y debilitamiento de los sindicatos. Las mujeres empresarias suelen proceder de la clase media y tienen expectativas acordes a las exigencias de la modernidad, pero deben apropiarse de las normas y códigos tradicionalmente establecidos para reproducirlos en el ámbito económico y social. Cabe mencionar que la principal fuente de financiamiento de las empresarias consiste en la reinversión de las ganancias en cuatro de cada cinco casos y para todos los tamaños de empresa, sin importar el monto de las ventas anuales. Los ahorros personales fueron considerados una fuente confiable de financiamiento, particularmente para las dueñas de micro y pequeñas empresas (INMUJERES 2010).

De esta argumentación se deriva un pensamiento peculiar, en que las funciones de liderazgo que actualmente las mujeres desempeñan tanto en las empresas privadas, la administración pública, la ciencia, la política, las artes y otros muchos ámbitos más aluden a un funcionamiento cultural y nos llevan a reconocer que ellas se han apropiado de símbolos que todavía aparecen en el campo del predominio masculino. Para el caso que nos ocupa, la incorporación de las mujeres en nuevos espacios de poder se incluye en el paquete emergente de transformaciones económicas, políticas y socioculturales de una sociedad que paulatinamente se incorpora a la modernidad." 


\section{REFERENCIAS}

Blanco, Mercedes (2009). Mujeres profesionistas de clase media: procesos de decisión e inserción laboral, en Revista Nueva Antropología, vol XVI, núm. 55, junio, pp. 27-42. https://revistascolaboracion.juridicas.unam.mx/index.php/nueva-antropologia

Castells, Manuel (1999). La era de la información: Economía, sociedad y cultura. El poder de la identidad, vol. II. México: Siglo XXI.

De la O, María Eugenia (2004). Las mujeres en la Sociología del Trabajo en México: entre De la O la indiferencia y el sobredimensionamiento. En Romo Pérez Gil, Sara Elena y Patricia Ravelo Blancas (comps.). Voces disidentes. Debates contemporáneos en los estudios de género en México. México: Miguel Ángel Porrúa.

García Guzmán, Brígida y Orlandina de Oliveira (2004). Trabajo femenino y vida familiar en México. México: COLMEX.

García Guzmán, Brígida y Edith Pacheco Gómez Muñoz (2007). Trabajo y familia en México. IV Conferencia Iberoamericana sobre Familia, Desempleo, Subdesempleo, Condiciones de Trabajo y Calidad de Vida. Bogotá: Universidad Externado de Colombia/Facultad de Trabajo Social. García Guzmán

García Guzmán, Brígida, Merces Blanco Sánchez y Edith Pacheco Gómez Muñoz (2009). Género y trabajo extradoméstico. En Brígida García Guzmán (coord.). Mujer: género y población en México. México: COLMEX/ Centro de Estudios Demográficos y de Desarrollo Urbano y Sociedad Mexicana de Demografía.

INEGI (2019) Encuesta nacional de ocupación y empleo.

Kantis, Hugo, Pablo Angelelli, y Francisco Gatto (2008). Nuevos emprendimientos y emprendedores. ¿De qué depende su creación y supervivencia? Explorando el caso argentino. En Proyecto de investigación organizado por el Small \& Medium Enterprises Advisory Group del Departamento de Desarrollo Sostenible del Banco Interamericano de Desarrollo y Coordinado a nivel regional por el Instituto de Industria de la Universidad Nacional de General Sarmiento.

Martínez, Griselda (2004). Empresarias y ejecutivas. Referencias organizacionales y ejercicio del poder. En Patricia Ravelo Blancas y Sara Elena Pérez (coords.). Voces disidentes: debates contemporáneos en los estudios de género en México. México: CIESAS.

Martínez, Alice (1993). La identidad femenina: crisis y construcción. En María Luisa Tarrés (comp.). La voluntad de ser. Mujeres en los noventa. México: COLMEX.

Massolo, Alejandra (2004). Una mirada de género a la ciudad de México (comp.). Los temas de la ciudad desde la perspectiva de género. México: UAM-Azcapotzalco.

Pacheco, E. y S. Parker (2016). Participación económica activa femenina en el México urbano. Un breve recuento y algunos hallazgos recientes, en Problemas del Desarrollo, vol. 27, núm; 1. México: UNAM/IIE.

Salles, Vania (2009). Cambios demográficos y socioculturales: familias contemporáneas en México.

Serna M. G. (1997) Mujeres empresarias en Córdoba-Orizaba, Veracruz.

Tarrés, María Luisa, (ed) (2001). Observar, escuchar y comprender: Sobre la tradición cualitativa en la investigación social. FLACSO.

Zabludovsky, Gina (1992). Empresarias y participación política en México. Ponencia presentada en el Latin American Studies Association. XVII Internacional Congress, en Los Ángeles, California, del 24 al 27 de septiembre.

ZABLUDOVSKY, Gina (2001). Las empresarias en México: una visión comparativa regional y global. México: COLMEX.

ZABLUDOVSKY, Gina (2013). "Empresarias y ejecutivas en México. Diagnósticos y desafíos". México: Instituto Panamericano de Alta Dirección de Empresas/ Plaza y Valdés. 